http://jurnaltarbiyah.uinsu.ac.id/index.php/raudhah

e-mail: jurnalraudhah@uinsu.ac.id

p-ISSN: 2338-2163

e-ISSN: $2716-2435$

\title{
Meningkatkan Penguasaan Kosa Kata Bahasa Inggris Menggunakan Media Audio Visual Pada Anak Usia 5-6 Tahun di RA Babussalam
}

\author{
${ }^{1}$ Humaidah Br Hasibuan \\ Universitas Islam Negeri Sumatera Utara \\ email: humaidah@uinsu.ac.id \\ ${ }^{2}$ Zulkipli Nasution \\ Universitas Islam Negeri Sumatera Utara \\ email: zulkipli_nasution@uinsu.ac.id \\ ${ }^{3}$ Miftahul Zannah \\ Universitas Islam Negeri Sumatera Utara \\ jannahmiftahul688@gmail.com
}

\begin{abstract}
Article received : 9 November 2020
Review process : 8 Januari 2021

Article accepted : 21 Januari 2021

Article published : 8 Maret 2021
\end{abstract}

\begin{abstract}
Abstrak
Penelitian ini bertujuan untuk meningkatkan penguasaan kosa kata bahasa Inggris melalui media audio visual pada anak usia 5-6 tahun di RA Babussalam. Penelitian ini berjenis penelitian tindakan kelas (PTK) dengan menerapkan dua siklus tindakan yang terdiri dari empat tahapan, yaitu: perencanaan, pelaksanaan tindakan, observasi, dan refleksi. Subjek pada penelitian ini yaitu: anak usia 5-6 tahun yang berjumlah 20 orang anak di RA Babussalam, sedangkan objek pada penelitian ini yaitu: media audio visual dan kosa kata bahasa Inggris. Instrumen yang digunakan pada penelitian ini yaitu lembar observasi. Teknik analisis data yang digunakan yaitu persentase rerata skor (P). Penelitian ini membuktikan bahwa: (1) kemampuan penguasaan kosa kata bahasa inggris awal anak pra siklus yaitu 20\% dengan rata-rata 3,45. Hal ini menunjukan bahwa kemampuan penguasaan kosa kata bahasa Inggris anak sangat rendah dan belum berkembang; (2) Terjadi peningkatan penguasaan kosa kata bahasa Inggris anak setelah menggunakan media audio visual yaitu dari $20 \%$ meningkat secara klasikal sebanyak $85 \%$. Hal ini menunjukkan bahwa dari penelitian yang dilakukan telah mencapai peningkatan keberhasilan secara klasikal.
\end{abstract}

Kata kunci: Kosa kata bahasa Inggris; Media audio visual; Raudhatul athfal

\begin{abstract}
This study aims to improve the mastery of English vocabulary through audio-visual media for children aged 5-6 years in RA Babussalam. This research is a classroom action research (CAR) by implementing two cycles of action consisting of four stages, namely: planning, implementing the action, observing, and reflecting. The subjects in this study were 20 children aged 5-6 years in RA Babussalam, while the objects in this study were audio-visual media and English vocabulary. The instrument used in this study was the observation sheet. The data analysis technique used is the percentage mean score $(P)$. This study proves that: (1) the pre-cycle children's ability to master English vocabulary is $20 \%$ with an average of 3.45. This shows that the ability of children's English vocabulary mastery is very low and underdeveloped; (2) There was an increase in
\end{abstract}

Meningkatkan Penguasaan Kosa Kata Bahasa Inggris Menggunakan Media Audio Visual Pada Anak Usia 5 -

6 Tahun di RA Babussalam

Copyright (c) 2021 Hasibuan, Nasution, Zannah, 
http://jurnaltarbiyah.uinsu.ac.id/index.php/raudhah

children's English vocabulary mastery after using audio-visual media, namely from $20 \%$ to a classical increase of $85 \%$. This shows that the research conducted has achieved an increase in classical success.

Keywords: English vocabulary; Audio-visual media; Raudhatul athfal

\section{A. PENDAHULUAN}

Menurut UU RI No. 20 Tahun 2003 tentang Sistem Pendidikan Nasional, Pendidikan Anak Usia Dini merupakan suatu upaya pembinaan yang ditujukan kepada anak sejak lahir sampai dengan usia enam tahun. Pendidikan tersebut dilakukan melalui pemberian rangsangan pendidikan untuk membantu pertumbuhan dan perkembangan jasmani dan rohani agar anak memiliki kesiapan dalam memasuki pendidikan lebih lanjut.

Pesatnya perkembangan kebutuhan teknologi di era globalisasi ini menuntut anakanak untuk dapat menguasai bahasa terutama Bahasa Inggris. Oleh karena itu mempelajari dan menguasai Bahasa Inggris sebagai alat komunikasi adalah hal yang sangat penting bagi anak untuk merespon tuntutan kemajuan zaman. Besarnya kebutuhan dan tuntutan untuk menguasai bahasa internasional di era globalisasi ini menyebabkan kurikulum pendidikan mulai mengalami perubahan. awalnya pelajaran Bahasa Inggris mulai diperkenalkan dari siswa kelas SMP, tetapi sekarang pelajaran Bahasa Inggris sudah mulai diperkenalkan dari sisswa kelas SD bahkan siswa yang masih duduk di usia Taman Kanak-kanak atau Play Group juga sudah mulai dipekenalkan dengan Bahasa Inggris dengan konteks pembelajaran belajar sambil bermain.

Menurut (Jazuly, 2016) pelajaran bahasa Inggris perlu diterapkan sejak dini agar anak lebih mudah mengembangkan bahasa Inggris di saat anak masuk ke Sekolah Dasar, SMP atau tingkat yang lebih tinggi. (Sari, 2012) mengemukakan bahwa kemampuan seseorang dalam menggunakan bahasa Inggris sangatlah dibutuhkan seiring dengan kemajuan sebuah negara. Karenanya pembelajaran bahasa Inggris sebagai bahasa Internasional mulai diperkenalkan sedini mungkin kepada anak didik. Menurut (Rahmawati, 2016) mengajarkan Bahasa Inggris menjadi daya tarik tersendiri bagi kalangan pengajar yang memiliki perhatian lebih terhadap pembelajaran bahasa asing bagi anak-anak dalam beberapa waktu ini. Terlebih hal itu didukung dengan fakta bahwa 
http://jurnaltarbiyah.uinsu.ac.id/index.php/raudhah

e-mail: jurnalraudhah@uinsu.ac.id

p-ISSN: 2338-2163

e-ISSN: $2716-2435$

sebagian besar orang tua memperkenalkan Bahasa Inggris sebagai bahasa asing, bahkan beberapa menjadikannya sebagai bahasa kedua sedini mungkin.

(Fauziati, 2010) mengemukakan bahwa anak-anak mempunyai kemampuan mengingat yang luar biasa khususnya usia 5-6 tahun. Sehingga masa tersebut adalah masa yang tepat dalam mengenalkan bahasa asing yang sesuai dengan kemampuan dan kebutuhan anak. Sedangkan menurut (Aminah, 2011), alasan pengajaran Bahasa Inggris pada anak usia dini diadakan ialah untuk memberikan kebutuhan pengetahuan Penguasaan Kosa-kata yang banyak sehingga apabila anak melanjutkan jenjang pendidikan ke tingkat yang lebih tinggi mereka tidak akan mengalami kesulitan.

Berdasarkan observasi yang saya lakukan di RA Babussalam terdapat 20 orang anak yang terdiri dari 9 anak laki-laki dan 11 anak perempuan. Terdapat 2 orang anak yang berkembang sangat baik (10\%), lalu terdapat 2 orang anak yang berkembang sesuai harapan (10\%), lalu terdapat 5 orang anak yang mulai berkembang (25\%), lalu terdapat 11 orang anak yang Belum Berkembang(55\%). Hal ini membuktikan bahwa Pengenalan terhadap penguasaan kosakata Bahasa Inggris di RA Babussalam dianggap masih kurang, baik melalui pembiasaan mendengar, pengucapan, maupun mengetahui arti dari setiap kata. Melihat kendala dan fenomena yang ada di lapangan tersebut, maka peneliti mencoba mencari berbagai macam media untuk membantu meningkatkan Penguasaan Kosakata Bahasa Inggris anak usia 5-6 tahun. Adapun media yang digunakan adalah Media Audio Visual yang digunakan untuk meningkatkan Penguasaan Kosakata Bahasa Inggris (vocabulary) melalui pembelajaran.

Dengan demikian dilakukan penelitian dengan judul upaya meningkatkan penguasaan kosa kata bahasa inggris melalui media audio visual pada anak usia 5-6 tahun di RA Babussalam.

\section{B. METODE PENELITIAN}

Jenis penelitian ini yaitu penelitian tindakan kelas (Classroom Action Research). Menurut (Maisarah, 2020) penelitian tindakan kelas (PTK) adalah penelitian yang menerapkan suatu tindakan untuk memecahkan masalah dan memperbaiki pembelajaran 
http://jurnaltarbiyah.uinsu.ac.id/index.php/raudhah

e-mail: jurnalraudhah@uinsu.ac.id

p-ISSN: 2338-2163

e-ISSN: $2716-2435$

yang terjadi di kelas. Penelitian ini dilakukan sebanyak dua siklus dengan empat tahapan pada setiap siklus, yaitu: perencanaan, pelaksanaan tindakan, observasi, dan refleksi. Tindakan yang diterapkan pada penelitian ini yaitu media audio visual, sedangkan masalah yang dipecahkan atau pembelajaran yang diperbaiki yaitu mengenai penguasaan kosa kata bahasa Inggris. Sedangkan subjek yang diteliti yaitu anak usia 5-6 tahun yang berjumlah 20 orang anak di RA Babussalam.

Instrumen yang digunakan untuk mengumpulkan data penelitian yaitu lembar observasi dan rubrik penilaian. Teknik analisis data yang digunakan yaitu persentase rerata skor $(\mathrm{P})$ dengan rumus sebagai berikut:

$$
\mathbf{P}=\frac{f}{n} \mathbf{x} 100 \%
$$

Keterangan :

P: Angka Persentase

f : Jumlah anak yang mengalami perubahan

$\mathrm{n}$ : Jumlah seluruh anak

\section{HASIL TEMUAN DAN PEMBAHASAN}

Penelitian dilakukan dalam II Siklus. Sebelum penelitian berlangsung peneliti melakukan observasi awal terhadap Penguasaan Kosa Kata Bahasa Inggris awal pada anak-anak di RA Babussalam. Berdasarkan observasi awal diitemukan bahwa masih rendahnya penguasaan kosa kata bahasa Inggris pada anak-anak di RA Babussalam, sebagaimana data pada tabel 1 dan gambar 1:

Tabel 1. Hasil Observasi Penguasaan Kosa Kata Bahasa Inggris Anak Pra Siklus

\begin{tabular}{|c|c|c|c|c|}
\hline No & Rata-Rata & Jumlah Anak & Persentase & Keterangan \\
\hline 1 & $9-10$ & 2 & $10 \%$ & Berkembang Sangat Baik (BSB) \\
\hline 2 & $6-8$ & 2 & $10 \%$ & Berkembang Sesuai Harapan (BSH) \\
\hline 3 & $3-5$ & 5 & $25 \%$ & Mulai Berkembang (MB) \\
\hline 4 & $0-2$ & 11 & $55 \%$ & Belum Berkembang (BB) \\
\hline \multicolumn{2}{|c|}{ Jumlah } & 20 & & 100 \\
\hline
\end{tabular}

Meningkatkan Penguasaan Kosa Kata Bahasa Inggris Menggunakan Media Audio Visual Pada Anak Usia 5 -

6 Tahun di RA Babussalam 
http://jurnaltarbiyah.uinsu.ac.id/index.php/raudhah e-mail: jurnalraudhah@uinsu.ac.id

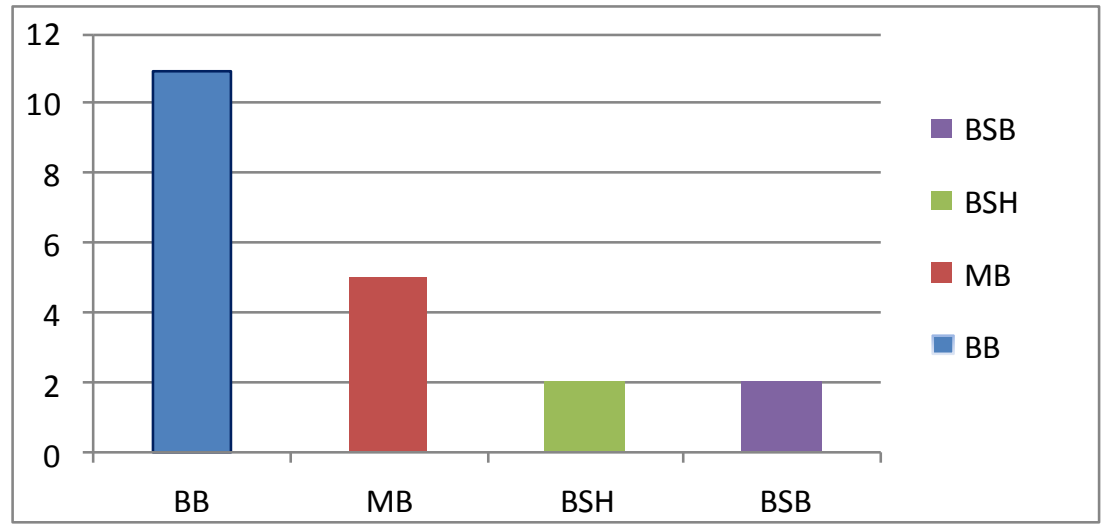

\section{Gambar 1. Hasil Observasi Penguasaan Kosa Kata Bahasa Inggris Anak Pra Siklus}

Tabel 1 dan gambar 1 menunjukkan bahwa hasil observasi awal sebagai data pra siklus hanya memperoleh $20 \%$ dengan rata-rata 3,45 hal ini menunjukan bahwa kemampuan penguasaan kosa kata bahasa Inggris anak sangat rendah dan belum berkembang. Penelitian dilanjutkan dengan menerapkan tindakan (yaitu penggunaan media audio visual) pada Siklus I yang hasil observasi pada siklus ini dapat dilihat pada tabel 2 dan gambar 2:

Tabel 2. Hasil Observasi Penguasaan Kosa Kata Bahasa Inggris Anak Siklus I

\begin{tabular}{|c|c|c|c|c|}
\hline No & Rata-Rata & Jumlah Anak & Persentase & Keterangan \\
\hline 1 & $9-10$ & 4 & 20 & Berkembang Sangat Baik (BSB) \\
\hline 2 & $6-8$ & 7 & 35 & Berkembang Sesuai Harapan (BSH) \\
\hline 3 & $3-5$ & 6 & 30 & Mulai Berkembang (MB) \\
\hline 4 & $0-2$ & 3 & 15 & Belum Berkembang (BB) \\
\hline \multicolumn{2}{|c|}{ Jumlah } & 20 & \multicolumn{2}{c}{} \\
\hline
\end{tabular}


http://jurnaltarbiyah.uinsu.ac.id/index.php/raudhah e-mail: jurnalraudhah@uinsu.ac.id

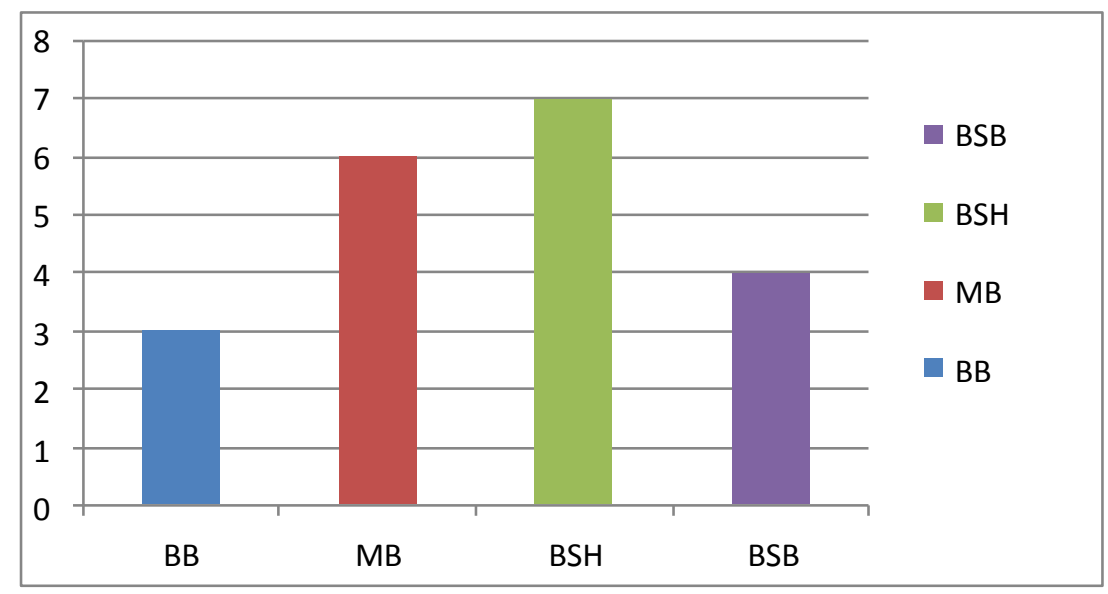

\section{Gambar 2. Hasil Observasi Penguasaan Kosa Kata Bahasa Inggris Anak Siklus I}

Tabel 2 dan gambar 2 menunjukkan bahwa pada siklus I terdapat 4 orang anak mempunyai kemampuan penguasaan kosa kata bahasa Inggris yang berkembang sangat baik (20\%), 7 orang anak yang berkembang sesuai harapan (35\%), 6 orang anak yang mulai berkembang (30\%), dan 3 orang anak yang Belum Berkembang (15\%). Persentase Kemampuan Klasikal (PKK) yang diperoleh pada siklus I yaitu sebesar 55\%. Karena PKK belum mencapai $80 \%$ maka tindakan yang menggunakan media audio visual dilanjutkan pada siklus II. Hasil observasi pada siklus II dapat dilihat pada tabel 3 dan gambar 3:

Tabel 3. Hasil Observasi Penguasaan Kosa Kata Bahasa Inggris Anak Siklus II

\begin{tabular}{|c|c|c|c|c|}
\hline No & Rata-Rata & Jumlah Anak & Persentase & Keterangan \\
\hline 1 & $9-10$ & 6 & 30 & Berkembang Sangat Baik (BSB) \\
\hline 2 & $6-8$ & 11 & 55 & Berkembang Sesuai Harapan (BSH) \\
\hline 3 & $3-5$ & 3 & 15 & Mulai Berkembang (MB) \\
\hline 4 & $0-2$ & 0 & 0 & Belum Berkembang (BB) \\
\hline \multicolumn{2}{|c|}{ Jumlah } & 20 & \multicolumn{2}{c}{} \\
\hline
\end{tabular}


http://jurnaltarbiyah.uinsu.ac.id/index.php/raudhah

e-mail: jurnalraudhah@uinsu.ac.id

p-ISSN: 2338-2163

e-ISSN: $2716-2435$

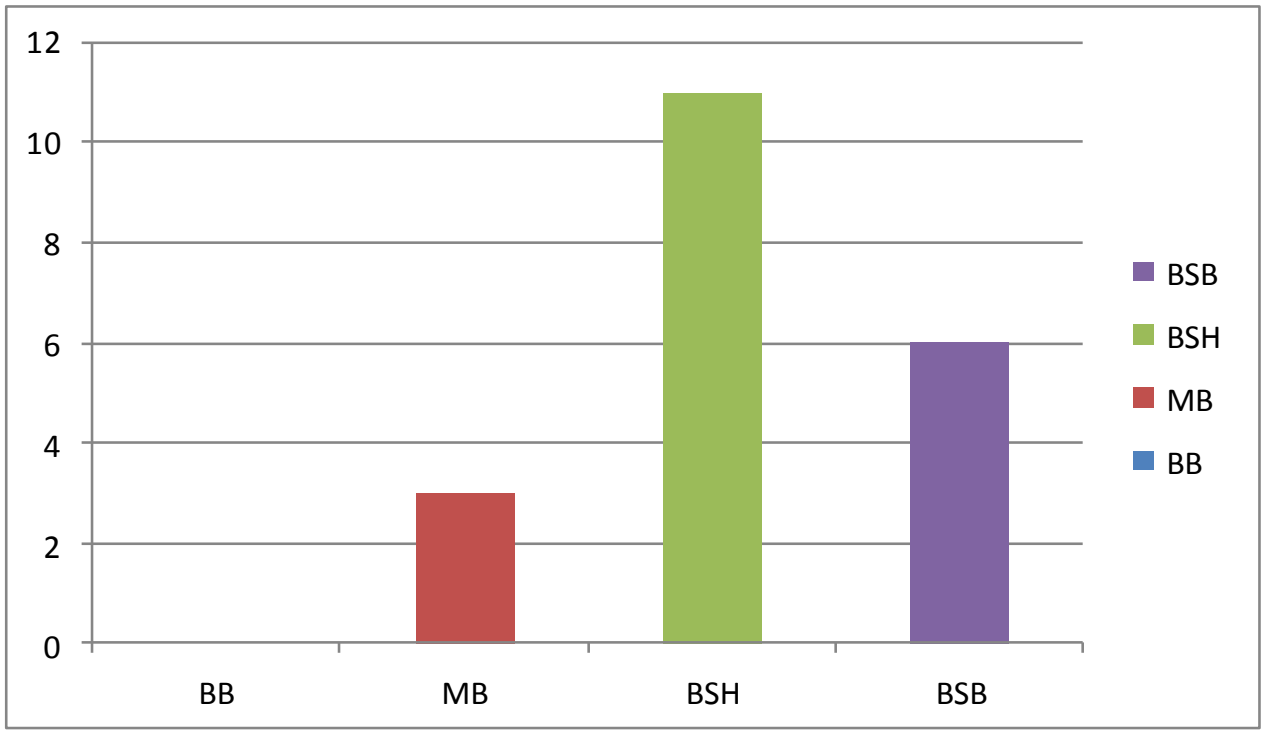

Gambar 3. Hasil Observasi Penguasaan Kosa Kata Bahasa Inggris Anak Siklus II

Tabel 3 dan gambar 3 menunjukkan bahwa pada siklus II terdapat 6 orang anak yang berkembang sangat baik (30\%), 11 orang anak yang berkembang sesuai harapan (55\%), 3 orang anak yang mulai berkembang (15\%), dan tidak terdapat anak yang belum berkembang (0\%). Persentase Kemampuan Klasikal (PKK) yang diperoleh pada siklus II yaitu sebesar $85 \%$. Karena PKK melebihi standar peningkatan (80\%) maka tindakan pada penelitian ini dicukupkan pada siklus II.

Berdasarkan hasil penelitian dapat disimpulkan bahwa terjadi peningkatan penguasaan kosa kata bahasa Inggris anak setelah menggunakan media audio visual yaitu dari $20 \%$ meningkat secara klasikal sebanyak $85 \%$. Hal ini menunjukkan bahwa dari penelitian yang dilakukan telah mencapai peningkatan keberhasilan secara klasikal. Hasil pada penelitian ini sejalan dengan penelitian yang dilakukan oleh (Marlianingsih, 2016) yang membuktikan bahwa penggunaan media audio visual animasi untuk meningkatkan penggunaan kosakata bahasa Inggris meningkat dan sangat baik terlihat ketika anak menjadi antusias dan tidak cepat merasa bosan.

Menurut Zaman dalam (Guslinda \& Kurnia, 2018) media audio visual adalah kombinasi antara media audio dan media visual atau biasa disebut media pandang dengar. Ia mengatakan bahwa penggunaan media audio visual ini dapat penyajian isi tema kepada 
http://jurnaltarbiyah.uinsu.ac.id/index.php/raudhah

e-mail: jurnalraudhah@uinsu.ac.id

p-ISSN: 2338-2163

e-ISSN: $2716-2435$

anak akan semakin lengkap dan optimal. Sealin itu media ini dalam batasan-batasan tertentu dapat juga menggantikan peran dan tugas guru. (Maisarah, 2019) mengemukakan kriteria memilih dan atau membuat media, antara lain: ketepatan tujuan pembelajaran, kedalaman bahan ajar, media yang digunakan efisien (mudah diperoleh, murah, sederhana, praktis), dan kesesuaian tahap perkembangan anak. Media audio visual yang digunakan pada penelitian ini telah memenuhi beberapa kriteria, yaitu: ketepatan tujuan dan kedalaman bahan ajar untuk penguasaan kosa kata bahasa Inggris pada anak usia dini, media yang digunakan efisien karena langsung didesain sepraktis mungkin, dan telah disesuaikan untuk tahap perkembangan anak usia dini khususnya usia 5-6 tahun.

\section{SIMPULAN DAN SARAN}

Temuan penelitian menyimpulkan beberapa hal, yaitu: (1) kemampuan penguasaan kosa kata bahasa inggris awal anak pra siklus yaitu 20\% dengan rata-rata 3,45. Hal ini menunjukan bahwa kemampuan penguasaan kosa kata bahasa Inggris anak sangat rendah dan belum berkembang; (2) Terjadi peningkatan penguasaan kosa kata bahasa Inggris anak setelah menggunakan media audio visual yaitu dari 20\% meningkat secara klasikal sebanyak $85 \%$. Hal ini menunjukkan bahwa dari penelitian yang dilakukan telah mencapai peningkatan keberhasilan secara klasikal.

Dari hasil penelitian ini disampaikan beberapa saran, yaitu: (1) kepada orang tua, sebaiknya memfasilitasi anak untuk menguasai bahasa asing seperti bahasa Inggris. Karena bahasa Inggris merupakan bahasa Internasional dan anak usia dini berada di masa golden age dimana anak lebih mudah menyerap hal-hal baru termasuk bahasa asing; (2) gepada guru, sebaiknya lebih menginovasikan pembelajaran dan kreatif, terutama dalam hal penguasaan kosa kata bahasa inggris pada anak sejak dini. Khususnya dalam hal penggunaan media pembelajaran yang menarik perhatian anak, mendukung pencapaian tujuan pembelajaran, dan meningkatkan rasa senang belajar pada diri anak seperti halnya media audio visual. Dengan demikian, bukan hanya kemampuan kosa kata bahasa Inggris yang akan meningkat tetapi juga aspek perkembangan lainnya; dan (3) kepada kepala sekolah/ketua yayasan, dalam proses pembelajaran media pembelajaran sangatlah

Meningkatkan Penguasaan Kosa Kata Bahasa Inggris Menggunakan Media Audio Visual Pada Anak Usia 5 -

6 Tahun di RA Babussalam

Copyright (c) 2021 Hasibuan, Nasution, Zannah, 
http://jurnaltarbiyah.uinsu.ac.id/index.php/raudhah

e-mail: jurnalraudhah@uinsu.ac.id

p-ISSN: 2338-2163

e-ISSN: $2716-2435$

dibutuhkan oleh anak. Sebab anak akan lebih paham belajar secara nyata/langsung. Untuk itu kepala sekolah/yayasan harus bisa memberikan fasilitas terbaik bagi anak untuk mendukung proses pembelajaran anak dengan baik, dan mendorong guru untuk aktif, inovatif dan kreatif dalam menyampaikan pembelajaran kepada anak menggunakan media pembelajaran.

\section{DAFTAR PUSTAKA}

Aminah, S. (2011). Penggunaan Media Gambar untuk Meningkatkan Penguasaan Kosakata Bahasa inggris Anak Kelas B di TK Aisyiyah Pantirejo Sragen Tahun Pelajaran 2010/2011. Universitas Muhammadiyah Surakarta.

Fauziati, E. (2010). Teaching English as a Foreign Language (TEFL). Surakarta: Era Pustaka Utama.

Guslinda, \& Kurnia, R. (2018). Media Pembelajaran Anak Usia Dini. Surabaya: Jakad Publishing.

Jazuly, A. (2016). Peran Bahasa Inggris Pada Anak Usia Dini. Jurnal Pendidikan Dompet Dhuafa, 6(1). https://jurnal.makmalpendidikan.net/index.php/JPD/article/view/8

Maisarah. (2019). Matematika dan Sains Anak Usia Dini (Edisi Revisi). Medan: Akasha Sakti.

Maisarah. (2020). PTK dan Manfaatnya Bagi Guru. Bandung: Media Sains Indonesia.

Marlianingsih, N. (2016). Pengenalan Kosa Kata Bahasa Inggris Melalui Media Audio Visual (Animasi) di PAUD. Faktor: Jurnal Ilmiah Kependidikan, 3(2). https://doi.org/10.30998/fjik.v3i2.782

Rahmawati, E. (2016). How Children Learn A Foreign Language (A Literature Study on Teaching English to Young Learners). As-Sibyan: Jurnal Pendidikan Anak Usia Dini, 1(2). http://jurnal.uinbanten.ac.id/index.php/assibyan/article/view/198

Sari, M. (2012). Peningkatan Pengenalan Bahasa Inggris Pada Anak dengan Total Pshycal Response di Taman Kanak-Kanak Negeri Pembina Kabupaten Sijunjung. Jurnal Pesona PAUD, 1(1). https://doi.org/10.24036/1590

Meningkatkan Penguasaan Kosa Kata Bahasa Inggris Menggunakan Media Audio Visual Pada Anak Usia 5 -

6 Tahun di RA Babussalam Copyright (c) 2021 Hasibuan, Nasution, Zannah, 